\title{
Business Process Outsourcing: Lessons From Case Studies In India, Poland, And Canada
}

Steven H. Appelbaum, Concordia University, Canada Anis Samaha, Pratt \& Whitney Canada Corp, Canada

\begin{abstract}
The objective of this article is to study the effectiveness of the company-partner relationship when outsourcing business processes in a large aerospace company. The intent is to supplement existing anecdotal evidence with data collected through a structured methodology in an effort to highlight process inefficiencies that may lead to hidden costs. Recommendations are provided to management as a means of addressing the process gaps to improve productivity. A literature review was conducted and a selection of findings from relevant papers and studies were retained as best practices for a successful outsourcing venture. These findings were then used to generate questions as part of a survey. The latter was distributed to 90 employees and managers from both the company and the vendor with the purpose of identifying gaps with the literature. A mismatch between the survey results and the literature would signal an improvement opportunity requiring management of attention. Although the overall health of the outsourcing process is satisfactory, several aspects of the working relationship were found to be deficient and the cause of inefficiencies (i.e. loss time, frustration, increased cost ...). In particular, employees from both sides found a lack in upfront planning, communication of expectations, and information sharing. Furthermore, both employees and managers expressed concern about the need for training to better deal with cultural differences and motivation.
\end{abstract}

Keywords: Business Process Outsourcing, Strategic Alliances, Partnerships, Culture, International Business, Globalization.

\section{INTRODUCTION}

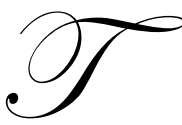

he concept of outsourcing has existed for centuries. In his book, The World is Flat, Thomas Friedman takes us through the history and evolution of outsourcing from the days of Christopher Columbus to a modern call center in Bangalore, India. Friedman argues, through statistics, interviews and case studies, that the modern wave of outsourcing is quite different than those of the past. The world has become "flat" in the sense that these forces have converged to level the competitive playing field between developed and emerging countries. In a "flat" world, the traditional business model can no longer apply. It becomes imperative that companies adapt their structure and operations in order to survive in this new business reality. Vertical operating structures where collaboration is top-down within the company have to give way to an increasingly horizontal structure where collaboration occurs globally across different departments, suppliers, and partners.

Today everything from purchasing to payroll, human resource management to information technology, research \& development to engineering tasks is being outsourced to the four corners of the world. In fact, it has become possible to outsource virtually any part of a business. Outsourcing is most commonly used when a company wants to reduce cost and improve quality by leveraging the expertise of specialized vendor. However, outsourcing strategies have become much more complex as companies are attempting to achieve numerous other objectives (J. Linder et al., 2002). In a study conducted by Elmuti and Kathawala (2000), the top reasons for outsourcing included 
the desire for companies to gain access to foreign resources and raw materials while establishing a presence in developing markets. This suggests that outsourcing is undertaken for more than just cost reduction or quality improvement; it has rather become an integral part of a company's strategy. This new approach has transformed the traditional company-vendor relationship. Strategic alliances and partnerships have become crucial for companies to create value through innovation while remaining competitive. The company-vendor relationship is now highly dependent on the product being outsourced or service being provided. Figure 1 below shows four types of outsourcing relationships based on the different levels of "Specificity" and "Complexity" of the outsourced product or service (Franceschini et al., 2003).

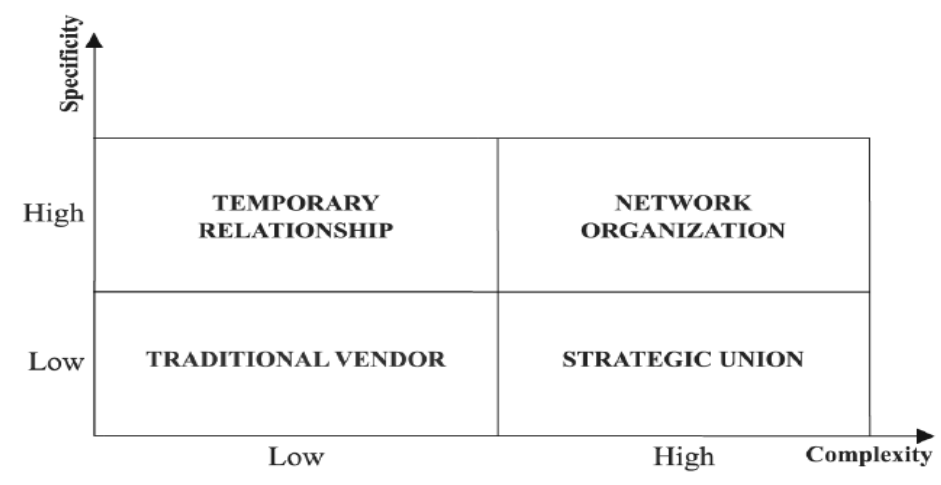

Figure 1: (Franceschini et al., 2003)

A product or service with a unique utilization purpose or that requires a unique set of skills to produce will have a high "Specificity". Whereas a product that has multiple uses and does not require a highly skilled workforce or advanced technology will have a low degree of "Specificity". On the other hand, "Complexity" refers to the level of difficulty in defining and monitoring the contractual expectations of the outsourcing process. In the Low-Low quadrant, the relationship is that of a traditional vendor where a short-term agreement is reached to produce or deliver a relatively simple product or service. There is little or no strategic thinking involved as the market offers several other alternatives. Here, the contractual agreements are clear and the chances of unplanned costs or delivery issues are low. As the product becomes more specific and the relationship more complex to manage, several concerns need to be considered. In a Strategic Union or a Network Organization, the company is fully invested in a long-term partnership with the strategic objective of joined value creation and improved future market position. In such a relationship, boundaries can become fuzzy and hidden costs may prove to be quite a burden. In fact, even though Business Process Outsourcing is an exponentially growing phenomenon, a number of players are now expressing concern and reluctance as the rewards they once were hoping to reap have not materialized. A survey by Deloitte Consulting (April 2005) of 25 large organizations with a combined $\$ 50$ billion in outsourcing contracts found that $70 \%$ have had negative experiences with outsourcing projects and are now taking a more cautious approach. One in four companies has brought outsourced functions back in-house and nearly half have failed to see the cost savings they anticipated as a result of outsourcing (Deloitte Consulting, 2005). Another study by the Diamond Consulting group (June 2005) shows that the number of buyers prematurely terminating an outsourcing relationship has doubled to 51 percent while the number of buyers satisfied with their service providers has plummeted from 79 percent to 62 percent (Diamond Consulting, 2005). These statistics warn of the temptation of outsourcing business processes and services without having properly considered and evaluated the hidden costs.

This case study and article focuses on the Business Process Outsourcing activities of a large Aerospace company. Section 2 briefly describes the company in question and introduces the issues around which the study is focused. Section 3 contains a literature search aimed at extracting relevant data gathered from studies, surveys, or real-life experiences. This data is then used to formulate a set of hypotheses against which the company's performance will be measured as a means of identifying gaps and problem areas. These hypotheses are then used to 
develop a questionnaire that will be used to gather empirical data from company employees through a survey-based method. The result of the survey are presented and analyzed where a link between the gathered data and the appropriate hypothesis is established. Finally, a summary, conclusions and a set of recommendations to address the main gaps identified in the study.

\section{ISSUES TO BE ANALYZED}

Aerospace Logistics Ltd. (AL Ltd.) is a world leader in the design and production of small and medium gas turbine engines for business and regional aircrafts. With over 50,000 engines produced over the past 80 years operating on 19,000 aircrafts, AL Ltd. customers can be found all over the globe. AL Ltd. employs over 10,000 people world-wide with about 7,000 working at the headquarters plant in North America. Employees in the Engineering office make-up three distinct groups: managers, engineers, and technical assistants. With a growing global customer base, fierce competition, and an urgent need for a leaner cost structure, AL Ltd. has been expanding its operations in developing countries. By outsourcing a selection of engineering business process tasks, AL Ltd. is hoping to achieve cost reductions while strengthening its presence in emerging markets. In 2003, AL Ltd. opened its first Satellite Engineering Office (SEO) in India where engineering analysis work would be conducted as a way of relieving headquarters from lengthy and repetitive tasks. In 2005, the second SEO was founded in Europe for assisting with drafting and configuration management jobs.

Since their foundation, both offices have continuously grown in size and have become a natural part of the organization. Workers at the SEO's are considered to be AL Ltd. employees with the same benefits but not the same privileges for accessing proprietary information. The relationship between AL Ltd. and the SEO's has developed into a "Network Organization" due to the high specificity and complexity of the services provided. There are no outlined contractual deliverables or boundaries as the relationship is fluid and continuously evolving to meet new demands. The unwritten expectation is that AL Ltd. provides the SEO's with the proper information, required training, and adequate support to do the job. On the other hand, the SEO's are expected to complete the tasks they are assigned in a timely manner and to the AL Ltd. quality standards.

Having a network organization with fuzzy or ill-defined boundaries has its advantages but also carries with it many disadvantages and pitfalls. Anecdotal data informally collected by the authors through interaction with AL Ltd. colleagues has revealed a general sense of employee frustration due to the inefficiencies of the outsourcing process.

The objective of this research paper is to explore the AL Ltd.-SEO relationship in an attempt to identify the drivers that lead to process inefficiencies and hidden costs. Based on our findings, we will propose a set of recommendations to improve the efficacy of the outsourcing process.

\section{SYNTHESIS OF LITERATURE REVIEW}

This section will focus on the review of available research of essential papers and studies deemed to be directly related to the relevant issues affecting the productivity of the company-vendor relationship leading to unplanned costs. In particular, the day-to-day operations are often plagued with administrative, technical, as well as cultural problems causing deterioration in the personnel relationship and a decrease in productivity. The findings were grouped into three distinct categories found to be the major drivers: 1) outsourcing and distance management, 2) cultural differences, and 3) motivation. Based on the literature that was reviewed, a set of hypotheses was developed as a means of capturing the pertinent conclusions and experiences. The hypothesis format was used as a way of raising an issue or a concern that could be pertinent to this study and its objective of focusing in on the drivers of process inefficiency. By leveraging the vast amount of research conducted on the subject, the hypotheses serve as a means of identifying the known issues that are applicable to AL Ltd. and the ones that perhaps may not be relevant. The latter distinction is validated through the collection of empirical data that will be compared to the literature findings. The empirical data is gathered based on a set of questions that are intended to answer or validate each hypothesis. In total, fourteen hypotheses were created from the literature review and are listed below: 
H1. Poor efficiency of the outsourcing process is caused by a lack of upfront planning of requirements and expectations.

H2. Poor efficiency of the outsourcing process is caused by misevaluation of the vendor's skills and capabilities.

H3. Poor efficiency of the outsourcing process is caused by a lack of close management and improvement of the customer-vendor relationship.

H4. Poor efficiency of the outsourcing process is caused by a lack of proper management training in order to efficiently deal with cultural differences.

H5. The efficiency of the outsourcing process is dependent on the quality of shared information and the dedication of key players.

H6. Poor efficiency of the outsourcing process is caused by poor communication, different interpretations of quality and time schedule expectations, and by information security and confidentiality constraints.

H7. Poor efficiency of the outsourcing process is caused by mismanagement of the human resource aspect.

H8. Poor efficiency of the outsourcing process is caused by a higher Power Distance index in India and Poland.

H9. Poor efficiency of the outsourcing process is caused by a difference in the Individual index between Canada and the SEO countries.

H10. Poor efficiency of the outsourcing process is caused by a difference in the Masculinity index between Canada and the SEO countries.

H11. Poor efficiency of the outsourcing process is caused by a difference in the Uncertainty Avoidance Index (UAI) index between Canada and the SEO countries.

H12. Outsourcing is a cause of low employee morale and motivation.

H13. Outsourcing is a cause of increase in turnover rate and an eventual depletion of highly skilled and experienced workforce.

H14. Incentive programs and enriching intrinsic motivation positively affect employee job satisfaction.

Table 1 below contrasts the relationship between the literature findings, the derived hypotheses, and the empirical questions that will reveal whether each hypothesis is applicable to this case study. 
Table 1: Link between literature findings, research hypotheses, and survey questions

\begin{tabular}{|c|c|c|}
\hline Literature Review Findings & Hypotheses & Questionnaire / Data Gathering \\
\hline \multicolumn{3}{|l|}{ Outsourcing / Distance Management } \\
\hline $\begin{array}{l}\text { Developing a comprehensive plan outlining detailed } \\
\text { expectations, requirements, and expected benefits may be the } \\
\text { key to successful outsourcing efforts (Guterl, 1996; Peisch, } \\
\text { 1995; Power et al., 2004). }\end{array}$ & $\begin{array}{l}\text { H1: Poor efficiency of the outsourcing process is } \\
\text { caused by a lack of upfront planning of requirements } \\
\text { and expectations. }\end{array}$ & $\begin{array}{l}\text { To } \boldsymbol{A L} \text { Ltd. \& SEO: Was there a plan developed prior to } \\
\text { starting the work? This plan should have outlined the } \\
\text { respective responsibilities, requirements, expectations, and } \\
\text { benefits. }\end{array}$ \\
\hline $\begin{array}{l}\text { Although one of the main advantages for choosing to } \\
\text { outsource is leveraging a highly skilled workforce, some } \\
\text { studies have found that the expertise of the staff can } \\
\text { sometimes be over-evaluated or misunderstood (Lacity and } \\
\text { Hirschheim, 1993; Earl, 1996). }\end{array}$ & $\begin{array}{l}\text { H2: Poor efficiency of the outsourcing process is } \\
\text { caused by misevaluation of the vendor's skills and } \\
\text { capabilities. }\end{array}$ & $\begin{array}{l}\text { To AL Ltd.: Using the following criteria, how would you rate } \\
\text { your satisfaction with the work done in each satellite office? } \\
\text { - Technical knowledge } \\
\text { - Accuracy of estimates } \\
\text { - Responsiveness to queries } \\
\text { - Interpretation of results } \\
\text { - Effectiveness of recommendation }\end{array}$ \\
\hline $\begin{array}{l}\text { Literature points to the importance of a well-managed and } \\
\text { closely monitored customer-vendor relationship (Earl, 1996; } \\
\text { Embleton and Wright, 1998). Being flexible in the sense of } \\
\text { continuously improving the process is another key aspect of } \\
\text { success (Lankford and Parsa, 1999) }\end{array}$ & $\begin{array}{l}\text { H3: Poor efficiency of the outsourcing process is } \\
\text { caused by a lack of close management and } \\
\text { improvement of the customer-vendor relationship. }\end{array}$ & $\begin{array}{l}\text { To AL Ltd.: Do you feel that the relationship with the SEO's } \\
\text { is closely managed and continuously improved? If possible, } \\
\text { please provide examples. } \\
\text { To } S E O \text { : Do you feel that the relationship with AL Ltd. is } \\
\text { closely managed and continuously improved? If possible, } \\
\text { please provide examples. }\end{array}$ \\
\hline $\begin{array}{l}\text { Providing managers with skills that will enable them to adopt } \\
\text { other cultures and work with foreign managers may be very } \\
\text { important to ensure the success of outsourcing (Sullivan and } \\
\text { Tu, 1995). }\end{array}$ & $\begin{array}{l}\text { H4: Poor efficiency of the outsourcing process is } \\
\text { caused by a lack of proper management training in } \\
\text { order to efficiently deal with cultural differences. }\end{array}$ & $\begin{array}{l}\text { To AL Ltd. Managers: Have you received the proper training } \\
\text { to efficiently manage cultural differences? } \\
\text { To SEO Managers: Have you received the proper training to } \\
\text { efficiently manage cultural differences? }\end{array}$ \\
\hline $\begin{array}{l}\text { The quality of the relationship will depend on the quality of } \\
\text { information sharing, the attitudes and dispositions of the key } \\
\text { players, and the social climate within which relationships are } \\
\text { pursued. (Bensaou, 1999). }\end{array}$ & $\begin{array}{l}\text { H5: The efficiency of the outsourcing process is } \\
\text { dependent on the quality of shared information and the } \\
\text { dedication of key players. }\end{array}$ & $\begin{array}{l}\text { To AL Ltd.: a) How would you rate your satisfaction with } \\
\text { information sharing from the SEO offices? } \\
\text { b) How would you rate your satisfaction with the level of } \\
\text { support received from each satellite office? } \\
\text { c) How would you rate your satisfaction with the working } \\
\text { professionalism in each satellite office? } \\
\text { To SEO: a) How would you rate your satisfaction with } \\
\text { information sharing from AL Ltd.? } \\
\text { b) How would you rate your satisfaction with the level of } \\
\text { support received from AL Ltd.? } \\
\text { c) How would you rate your satisfaction with the working } \\
\text { professionalism at AL Ltd.? }\end{array}$ \\
\hline $\begin{array}{l}\text { Problems can arise regarding communication, confidentiality, } \\
\text { security, quality expectations, and time schedules (Ramarapu } \\
\text { et al., 1997). }\end{array}$ & $\begin{array}{l}\text { H6: Poor efficiency of the outsourcing process is } \\
\text { caused by poor communication, different } \\
\text { interpretations of quality and time schedule } \\
\text { expectations, and by information security and } \\
\text { confidentiality constraints. }\end{array}$ & $\begin{array}{l}\text { To AL Ltd.: Using the following criteria, how would you rate } \\
\text { your satisfaction with the work done in each satellite office? } \\
\text { - Quality of product / service } \\
\text { - Delivery of product / service (i.e. schedule) } \\
\text { - Communication (oral) } \\
\text { - Communication (written) } \\
\text { To AL Ltd.: Do you find it difficult to share information with }\end{array}$ \\
\hline
\end{tabular}




\begin{tabular}{|c|c|c|}
\hline Literature Review Findings & Hypotheses & Questionnaire / Data Gathering \\
\hline & & $\begin{array}{l}\text { the SEO's due to proprietary or confidentiality reasons? Does } \\
\text { this affect the efficiency of their work? } \\
\text { To SEO: Do you feel that you are not given complete } \\
\text { information to do your work due to proprietary or } \\
\text { confidentiality reasons? Does this affect the efficiency of your } \\
\text { work? }\end{array}$ \\
\hline $\begin{array}{l}\text { The human resource dimensions of outsourcing, including } \\
\text { retention of capabilities and skills, is mismanaged or } \\
\text { overlooked by a number of organizations (Currie and } \\
\text { Willcocks, 1997). }\end{array}$ & $\begin{array}{l}\text { H7: Poor efficiency of the outsourcing process is } \\
\text { caused by mismanagement of the human resource } \\
\text { aspect. }\end{array}$ & $\begin{array}{l}\text { To AL Ltd. \& SEO: Do you feel that enough attention was/is } \\
\text { given to the human resource aspect of outsourcing? This } \\
\text { includes accounting for cultural differences, retaining talent, } \\
\text { training, etc... }\end{array}$ \\
\hline \multicolumn{3}{|l|}{ Cultural Differences } \\
\hline $\begin{array}{l}\text { Hofstede's study shows that the Power Distance Index (PDI) } \\
\text { is extremely high in India ( } 72 \text { ) followed by Poland (50), and } \\
\text { then Canada (35). (Hofstede, 1981; www.geert-hofstede.com) } \\
\text { Implications: SEO workers will be less prone to questioning } \\
\text { the authority of head office and afraid/shy to ask for } \\
\text { assistance. }\end{array}$ & $\begin{array}{l}\text { H8: Poor efficiency of the outsourcing process is } \\
\text { caused by a higher PD index in India and Poland. }\end{array}$ & $\begin{array}{l}\text { To } \boldsymbol{A L} \text { Ltd.: Do you feel that SEO employees are less prone to } \\
\text { questioning instructions or asking for assistance than your } \\
\text { Canadian co-workers? } \\
\text { To } S E O \text { : Do you feel comfortable in asking for help when you } \\
\text { are unclear about the instructions you were given? }\end{array}$ \\
\hline $\begin{array}{l}\text { Hofstede's study shows that Individualism (IDV) is distinctly } \\
\text { higher in Canada (75), followed by Poland (55), and then } \\
\text { India (43). (Hofstede, 1981; www.geert-hofstede.com) } \\
\text { Implications: - Canadians will expect their foreign } \\
\text { counterparts to work somewhat independently. } \\
\text { - Indians, slightly more than Poles, will expect guidance from } \\
\text { head office. } \\
\text { - Indians, slightly more than Poles, will expect to be part of } \\
\text { the decision making process. } \\
\text { - The concept of shared responsibility will be more prevalent } \\
\text { in India and Poland as opposed to individual responsibility in } \\
\text { Canada. }\end{array}$ & $\begin{array}{l}\text { H9: Poor efficiency of the outsourcing process is } \\
\text { caused by a difference in the IDV index between } \\
\text { Canada and the SEO countries. }\end{array}$ & $\begin{array}{l}\text { To AL Ltd.: a) Are the SEO offices autonomous in their } \\
\text { work? } \\
\text { b) Do you feel that individuals in the SEO offices are } \\
\text { responsible and accountable for their own work? }\end{array}$ \\
\hline $\begin{array}{l}\text { Hofstede's study shows that the Masculinity index (MAS) is } \\
\text { similar in Canada (48) and India (50), but slightly higher in } \\
\text { Poland (60). (Hofstede, 1981; www.geert-hofstede.com) } \\
\text { Implications: In Poland, earnings, recognition and } \\
\text { advancement are important to employees. Whereas in India } \\
\text { and Canada, cooperation and security are more valued by } \\
\text { employees. }\end{array}$ & $\begin{array}{l}\text { H10: Poor efficiency of the outsourcing process is } \\
\text { caused by difference in the MAS index between } \\
\text { Canada and the SEO countries. }\end{array}$ & $\begin{array}{l}\text { To AL Ltd. \& SEO: Please rank the following in order of } \\
\text { importance to you: earnings, cooperation among colleagues, } \\
\text { recognition, job security, career advancement. }\end{array}$ \\
\hline $\begin{array}{l}\text { Hofstede's model shows that the Uncertainty Avoidance Index } \\
\text { (UAI) is quite high in Poland (72) compared to Canada (42) } \\
\text { and India (35) who shares a similar score. } \\
\text { (Hofstede, 1981; www.geert-hofstede.com) } \\
\text { Implications: - Indian employees are more likely to take risks }\end{array}$ & $\begin{array}{l}\text { H11: Poor efficiency of the outsourcing process is } \\
\text { caused by a difference in the UAI index between } \\
\text { Canada and the SEO countries. }\end{array}$ & $\begin{array}{l}\text { Data Gathering } \\
\text { Collect statistics on turnover rate in India and in Poland } \\
\text { offices in order to validate hypothesis. }\end{array}$ \\
\hline
\end{tabular}




\begin{tabular}{|c|c|c|}
\hline Literature Review Findings & Hypotheses & Questionnaire / Data Gathering \\
\hline $\begin{array}{l}\text { and frequently change jobs than are Polish employees. } \\
\text { - Indian employees are more likely to be comfortable in } \\
\text { unstructured situation where they may lack "big picture" } \\
\text { visibility. }\end{array}$ & & $\begin{array}{l}\text { To SEO: Are you being asked to work on specific tasks } \\
\text { without being given an appreciation of the entire project? If } \\
\text { so, how does that affect your work? }\end{array}$ \\
\hline \multicolumn{3}{|l|}{ Motivation } \\
\hline $\begin{array}{l}\text { Outsourcing can have a negative effect on the morale of } \\
\text { company employees and can lead to fear, insecurity, } \\
\text { uncertainty, frustration, resentment, and anger (Embleton and } \\
\text { Wright, 1998; Elmuti and Kathawala, 2000). } \\
\text { Research and experience indicate that outsourcing effectively } \\
\text { signals to employees the intention to instigate a change that } \\
\text { may involve de-skilling and, at worst, redundancies (Vail, } \\
\text { 1989). }\end{array}$ & $\begin{array}{l}\text { H12: Outsourcing causes a decrease in employee } \\
\text { morale and motivation. }\end{array}$ & $\begin{array}{l}\text { To } A \boldsymbol{L} \text { Ltd.: Do you feel less motivated at your job now that } \\
\text { you are working with a Satellite engineering office? Please } \\
\text { provide a detailed answer. }\end{array}$ \\
\hline $\begin{array}{l}\text { Those who witness outsourcing activities cannot help but } \\
\text { think how long the activity they perform will remain in-house. } \\
\text { Employees with self-confidence and marketable skills are } \\
\text { more likely to leave organizations and if they are key people, } \\
\text { then part of the memory of the organization disappears with } \\
\text { them, leaving the organizations vulnerable (De Vries and } \\
\text { Balazs, 1997). } \\
\text { Employees must feel that they are in control of their future } \\
\text { irrespective of whether they are laid off or not (Mishra et al., } \\
\text { 1998). }\end{array}$ & $\begin{array}{l}\text { H13: Outsourcing is a cause of increase in turnover } \\
\text { rate and an eventual depletion of highly skilled and } \\
\text { experienced workforce. }\end{array}$ & $\begin{array}{l}\text { To AL Ltd.: Do you feel safe concerning your future } \\
\text { employment at AL Ltd.? } \\
\text { To AL Ltd.: Would you consider leaving AL Ltd. for an equal } \\
\text { or better job at another company? }\end{array}$ \\
\hline $\begin{array}{l}\text { Incentive programs can positively affect motivation, } \\
\text { performance and interest within an organization. (Milne, } \\
\text { 2007) } \\
\text { Enriching the intrinsic motivators of recognition for good } \\
\text { performance, feeling of achievement and interesting and } \\
\text { challenging work will have greater impact on both improving } \\
\text { the level of job satisfaction and reducing the level of job } \\
\text { dissatisfaction than improving the salary levels. } \\
\text { (Savery, 1996) }\end{array}$ & $\begin{array}{l}\text { H14: Incentive programs and enriching intrinsic } \\
\text { motivation positively affect employee job satisfaction. }\end{array}$ & $\begin{array}{l}\text { Data Gathering } \\
\text { Collect information on incentive programs offered by AL } \\
\text { LTD. to company and SEO employees in order to validate } \\
\text { hypothesis. } \\
\text { To AL Ltd. \& SEO: Do you feel that AL Ltd. offers enough } \\
\text { incentive programs to encourage and reward you at your job? } \\
\text { To AL Ltd. \& SEO: How would you rate the following } 3 \\
\text { aspects of your job? Provide examples when possible. } \\
\text { - Recognition for good performance. } \\
\text { - Feeling of achievement. } \\
\text { - Interesting and challenging work. }\end{array}$ \\
\hline
\end{tabular}




\section{RESEARCH METHODOLOGY / DATA COLLECTION}

Table 1 summarized the questions that were designed from the literature-based hypotheses. These questions are structured in a way to encompass the main points raised by the literature while providing the content of the research survey. To test the hypotheses, a questionnaire will be sent out to employees from AL Ltd. and the Satellite offices as a means of gathering feedback. It is crucial that both sides are given a chance to express their concerns and provide their comments. It is also important that managers as well as working-level employees are surveyed. In total, 30 AL Ltd. managers and employees directly involved with SEO's were surveyed. From the Satellite offices, an equal number of supervisors and employees were asked to complete the questionnaire: 30 from the Polish office and 30 from the Indian office. The total respondents were 60.

\section{SURVEY RESULTS}

\section{DATA RELATED TO OUTSOURCING AND DISTANCE MANAGEMENT}

H1. Poor efficiency of the outsourcing process is caused by a lack of upfront planning of requirements and expectations.

The data collected shows that employees had little visibility or were not consulted concerning the upfront planning of the job. SEO employees complained that in some cases the requirements and expectations of a task were not made clear until the final review with AL Ltd. This would entail repeating part of or the entire job. Often, close guidance from AL Ltd. is required, which greatly affected autonomy and efficiency.

The data also shows that there is a lack in proper workload planning amongst the SEO discipline groups. AL Ltd. employees on the other hand find it frustrating when they receive general directives from their management such as "expanding work scope with SEO". These directives lack the details needed for establishing clear expectations. Therefore, employees are uncertain of which tasks can be outsourced or the level of involvement to be requested from the SEO.

H2. Poor efficiency of the outsourcing process is caused by misevaluation of the vendor's skills and capabilities.

AL LTD. employees and managers were asked to evaluate each SEO with respect to their perceived technical capabilities. The survey results are shown below.

\begin{tabular}{|l|c|c|}
\hline \multicolumn{1}{|c|}{ AL Ltd. Rating } & India & Poland \\
\hline Technical knowledge & 5.0 & 4.4 \\
\hline Accuracy of estimates & 4.0 & 3.5 \\
\hline Responsiveness to queries & 5.8 & 5.9 \\
\hline Interpretation of results & 4.0 & 3.5 \\
\hline Effectiveness of recommendation & 3.5 & 4.3 \\
\hline
\end{tabular}

Scale: 1 = Extremely Dissatisfied; 2 = Dissatisfied; 3 = Somewhat Dissatisfied; 4 = Neutral;

$5=$ Somewhat Satisfied; 6 = Satisfied (AL LTD. Standard); 7 = Extremely Satisfied.

Even though India was rated slightly better than Poland, the work done in both offices is not considered to be at AL Ltd. standard level (i.e. score of 6 or better), thus supporting this hypothesis. It is interesting to note that for this survey question employees at the SEO offices strongly voiced their concern with the lack of training and development. The main issues where:

- $\quad$ The lack of access to computer tools (limited by number of licenses), which impacts the time spent acquiring the computer skill. 
- $\quad$ The lack of access to certain information considered to be confidential or proprietary to AL Ltd. main office.

- $\quad$ Little exposure to the hardware. The designer does not see the part he is working on and therefore does not have an appreciation of his work.

- $\quad$ On-site AL Ltd. visits were cited as an important source of learning the AL Ltd. technical standards. However, not many visits were authorized over the past year.

H3. Poor efficiency of the outsourcing process is caused by a lack of close management and improvement of the customer-vendor relationship.

The answer from both sides was somewhat favourable concerning the management of the AL Ltd.-SEO relationship. The daily or frequent meetings were seen as a good forum for communicating progress and exchanging ideas. The recently implemented "Weekly Progress Report" from the SEO was also mentioned by the latter as an effective tool for provide work status as well as highlighting roadblocks in need of AL Ltd. management attention. Examples of process improvements in file transfers and information sharing were among the most cited.

H4. Poor efficiency of the outsourcing process is caused by a lack of proper management training in order to efficiently deal with cultural differences.

Across the board, managers answered that they have not received any type of training relating to outsourcing activities. The expectation was that managing and working with a foreign office should not be any different than what is done at home.

H5. The efficiency of the outsourcing process is dependent on the quality of shared information and the dedication of key players.

Survey participants were asked to evaluate their counterparts on three different criteria. Information Sharing consists of finding out if the SEO's are receiving the information required for doing their job and if this information is timely, complete and easy to understand. The results in the Table below show that both sides are neutral to somewhat satisfied with the current way information is shared. On the SEO side, the main issue was with accessing information through AL Ltd's intranet site or common databases. Not only was access highly restricted but downloading was slow and often interrupted by network failures. This meant that SEO employees would have to contact their focal point at AL LTD. in order to request the data, which often came too late or incomplete.

The Level of Support attempts to illustrate the availability and dedication of the staff at both locations. AL Ltd. employees are responsible for offering guidance and support to their counterparts and being available for answering questions. The scores in the Table below indicate that some improvement is required to ensure that both sides are providing the necessary support for an efficient operation. The availability of the AL Ltd. focal point was cited as a major concern for SEO employees. Whereas the low levels of knowledge and autonomy of some SEO employees was a cause for deficient support on behalf of the SEO's.

Professionalism was rated well across the board. Needless to say there are no issues at both offices with professional and courteous conduct.

\begin{tabular}{|l|c|c|c|c|}
\cline { 2 - 5 } \multicolumn{1}{c|}{} & \multicolumn{2}{c|}{ SEO Rating of AL LTD. } & \multicolumn{2}{c|}{ AL LTD. Rating of SEO } \\
\cline { 2 - 5 } \multicolumn{1}{c|}{} & India & Poland & 5.5 & Poland \\
\hline Information Sharing & 4.5 & 4.7 & 5.6 & 4.0 \\
\hline Level of Support & 4.8 & 5.2 & 5.8 & 6.1 \\
\hline Professionalism & 6.5 & 6.0 & & \\
\hline
\end{tabular}

Scale: 1 = Extremely Dissatisfied; 2 = Dissatisfied; 3 = Somewhat Dissatisfied; 4 = Neutral; 5 = Somewhat Satisfied; $6=$ Satisfied (AL LTD. Standard); 7 = Extremely Satisfied. 
H6. Poor efficiency of the outsourcing process is caused by poor communication, different interpretations of quality and time schedule expectations, and by information security and confidentiality constraints.

AL Ltd. participants were asked to rate the SEO's with respect to the delivery and quality of the product or service provided. Delivery was defined as meeting the agreed upon completion date, whereas Quality was defined as receiving a product that met AL Ltd. specifications with no further adjustments required. There is a clear difference between the two offices when it comes to quality. We must understand if this difference is due to the nature of the jobs, lack of training, or other causes. The delivery of the product is suffering in both offices. AL Ltd. employees have noted that this becomes frustrating when making client commitments that are dependent on the SEO performance.

Oral and written communication was highlighted as being an area in need of improvement. Information transmitted to the SEO's by email or phone can sometimes be misunderstood or misinterpreted and lead to significant errors and delays. In some cases, summary memos have to be completely re-written. The SEO employees have also identified language as being a significant barrier to effective communication.

The table below shows a summary of the scores for each evaluation criterion used by AL Ltd. to rate the SEO's.

\begin{tabular}{|l|c|c|}
\hline \multicolumn{1}{|c|}{ AL LTD. Rating } & India & Poland \\
\hline Quality of product / service & 6.0 & 4.6 \\
\hline Delivery of product / service & 4.6 & 3.9 \\
\hline Communication (oral) & 5.2 & 4.6 \\
\hline Communication (written) & 5.2 & 4.3 \\
\hline
\end{tabular}

Scale: 1 = Extremely Dissatisfied; 2 = Dissatisfied; 3 = Somewhat Dissatisfied; 4 = Neutral; 5 = Somewhat Satisfied;

$6=$ Satisfied (AL LTD. Standard); 7 = Extremely Satisfied.

Due to the high technology content of AL Ltd. products, some information or analysis tools are under confidentiality restrictions. They cannot be shared with the SEO or any other entity outside of AL Ltd. Survey candidates on both sides have described this issue as being a significant roadblock to job progress. In some cases, an SEO task has to be interrupted midway and transferred to AL Ltd. for work on a secured portion before it is sent back to the SEO for completion.

H7. Poor efficiency of the outsourcing process is caused by mismanagement of the human resource aspect.

Participants were asked if they felt that enough attention was or is given to the human resource aspect of outsourcing. This includes accounting for cultural differences, retaining talent, training, etc... The results are mixed and dependant on the AL Ltd. group the SEO is working with. AL Ltd. does not have a policy or guidelines on managing foreign human resources, nor is the HR department involved in daily outsourcing activities. In most cases, the responsibility for dealing with cultural issues, training, and retaining staff falls on the AL Ltd. Manager and his team. AL Ltd. participants felt that enough was being done to account for cultural differences. They also agreed that enough effort was placed on training SEO employees (lectures, on-the-job, and plant visits). The survey results from the SEO participants are in agreement when it comes to dealing with cultural differences. They cite that AL Ltd. is respectful of those differences and do their best to accommodate them. Training however was a point of contention. Some invested more time in training and mentoring their SEO counterparts, while others expected the SEO employees to learn on their own. Nevertheless, the consensus among SEO employees is that training is an area in need of significant improvement.

\section{DATA RELATED TO CULTURAL DIFFERENCES}

H8. Poor efficiency of the outsourcing process is caused by a higher Power Distance index in India and Poland.

The objective of this question was to determine the SEO worker's level of comfort in approaching his Canadian peers. Both India and Poland have a higher Power Distance index than Canada, which means that people 
are less prone to questioning the authority of their superiors. In fact, survey answers from AL Ltd. participants revealed frustration among AL Ltd. employees due to the lack of questions raised by SEO workers. This was more evident for the Indian office than the Polish office. It was AL Ltd's impression that SEO employees often walk away from a meeting without having fully understood AL Ltd. the details of the project at hand. They are reluctant to ask for clarification unless they are encouraged to do so by their AL Ltd. counterparts. In some cases, it was noted that the entire intent of a task was missed and had to be repeated. On the other hand, SEO survey participants did not share the same impressions. They noted that they felt comfortable asking questions or for help when unsure on how to proceed but that sometimes misunderstandings can occur due to language difficulties.

H9. Poor efficiency of the outsourcing process is caused by a difference in the Individual index between Canada and the SEO countries.

The Individualism index is distinctly higher in Canada than in India and Poland. This suggests Canadian workers are more likely to be independent in decision making and held accountable for their individual actions. When asked if the SEO offices are autonomous, AL Ltd. rated the Indian office at 4.3/7.0 and the Polish office at 3.4/7.0. These low scores indicate that AL Ltd. is somewhat dissatisfied with the autonomy of the satellite offices and finds that significant time is spent supporting the SEO's. Furthermore, when asked if foreign employees are responsible and accountable on an individual basis for their actions, the answer from AL Ltd. was somewhat more favorable. SEO employees were regarded as taking responsibility for their own work rather than hiding behind team decisions.

H10. Poor efficiency of the outsourcing process is caused by a difference in the MAS index between Canada and the SEO countries.

The Hofstede Masculinity (MAS) index is similar in Canada and India but higher in Poland. Candidates were asked to rank the following criteria in order of importance to them. According to the theory, countries with a higher MAS index will place more value on earnings, advancements, and individual recognition whereas countries with a lower MAS index will place more value on job security and cooperation among colleagues over other aspects. Survey candidates were asked to rank the following criteria in order of importance. The table below shows the results for each of the three offices.

\begin{tabular}{|l|l|l|l|}
\hline & \multicolumn{1}{|c|}{ Canada } & \multicolumn{1}{c|}{ India } & \multicolumn{1}{c|}{ Poland } \\
\hline $\mathbf{1}$ & Job security & Career advancement & Earnings \\
\hline $\mathbf{2}$ & Earnings & Earnings & Career advancement \\
\hline $\mathbf{3}$ & Recognition & Recognition & Recognition \\
\hline $\mathbf{4}$ & Career advancements & Cooperation among colleagues & Job security \\
\hline $\mathbf{5}$ & Cooperation among colleagues & Job security & Cooperation among colleagues \\
\hline
\end{tabular}

H11. Poor efficiency of the outsourcing process is caused by a difference in the Uncertainty Avoidance Index (UAI) index between Canada and the SEO countries.

The Uncertainty Avoidance Index (UAI) deals with a group's tolerance for uncertainty and ambiguity and indicates to what extent people feel either uncomfortable or comfortable in unstructured situations. From the data collected SEO employees are often placed in a situation where the data provided to them is somewhat incomplete or the objective of their task is not fully known. According to the Hofstede studies (1981), Poland's UAI index is almost double that of India's. In other words, employees from the Polish office should feel more stressed and frustrated in situations where incomplete information is given to them and the "big picture" is not always shared. On the other hand, India has quite a low UAI score indicating that Indians are more likely to feel comfortable in an unstructured environment. Canada's UAI score falls somewhere in between these two countries. 
Unanimously, SEO employees from both Poland and India agreed that they are not given the information required to efficiently do their job. Furthermore, they have expressed frustration when having to work on a specific task without knowing the value or the final intent of their work.

\section{DATA RELATED TO MOTIVATION}

H12. Outsourcing causes a decrease in employee morale and motivation.

AL Ltd. employees were asked if they felt less motivated at their jobs now that they are working with international satellite offices. A few have expressed concern about the uncertain future extent of outsourcing activities. However, 78\% responded that the satellite offices were seen as an extension of their own group rather than a replacement of it. Many cited examples where the SEO employees are adding significant value by taking on tasks that are time consuming and repetitive therefore freeing AL Ltd. employees to concentrate on the more challenging aspects of the job. In general, AL Ltd. employee morale and motivation do not seem to be affected as a consequence of outsourcing.

H13. Outsourcing is a cause of increase in turnover rate and an eventual depletion of highly skilled and experienced workforce.

For those who witness outsourcing, the thought of losing the job they perform daily is an important driver for considering employment elsewhere. AL Ltd. employees were asked if they felt safe about future employment at their company and if they would consider leaving the company for an equal or better job elsewhere. Seventy-two percent of AL Ltd. employees felt secure about their futures at the company and would not consider looking for another job. Furthermore, AL Ltd's staff levels and voluntary turnover rate have been stable over the past 5 years indicating that outsourcing initiatives have had no effect on employee turnover. These results corroborate well with the current boom in the aerospace industry and AL Ltd.'s recent success in securing several new contracts.

H14. Incentive programs and enriching intrinsic motivation positively affect employee job satisfaction.

AL Ltd. offers a number of incentive programs that apply to both AL Ltd. and SEO employees. Among those programs, education plays an important role as employees are given the opportunity to attend company sponsored university classes. Other training courses offered are also available for employees to further hone their technical as well as their business and interpersonal skills. AL Ltd. also offers an interesting home-work balance program where employees are given the opportunity to work from home on a need-to basis. Furthermore, the "Flex time" program all.ows employees who have worked more than the weekly required hours to accumulate their overtime and take it as a paid vacation. AL Ltd. also provides their employees with an attractive company savings plan as well as free financial advice for retirement planning. With AL Ltd. these incentive programs, AL Ltd. is well above the industry average in providing their employees with an enriched work experience. Survey results have shown that both AL Ltd. and SEO employees are satisfied with the incentives offered by their company.

Candidates were also questioned about the level of intrinsic motivation at the job. This includes recognition for good performance, feeling of achievement, and interesting and challenging work. Results showed $65 \%$ of AL Ltd. employees versus 54\% of SEO employees agree that they are being recognized for having done a good job. Once a year, employees from AL Ltd. and SEO offices meet with their manager for a performance evaluation and career planning. Many from both sides have cited the benefits of this meeting and the chance to go over their past year's achievements.

When asked to discuss their feeling of achievement at work, SEO employees from both countries overwhelmingly stated that the jobs they are being asked to work on are neither challenging nor interesting. They are often repetitive and do not add any value to the learning experience of each individual. Some recognize that this may be linked to the lack of training or expertise. 


\section{ANALYSIS OF DATA}

The results collected from the survey are discussed in this section in order to establish a congruency with the literature findings or to be more specific, with the associated hypotheses presented in previous sections.

\section{Analysis Of Data Related To Outsourcing And Distance Management (H1-H7)}

Hypothesis 1: This section concentrates on the analysis of the results pertaining to the outsourcing process and the challenges of managing employees at a distance. From the first hypothesis, concerning upfront process planning, the data shows that for existing repetitive tasks, the requirements and expectations have been established through time and experience. For new tasks, both sides find it difficult and frustrating to work without a clear understanding of the expectations. In fact, it becomes extremely difficult to manage work distribution (or workflow), plan manpower location, and schedule deliverables when the project expectations are ill defined. Several research studies have found that planning ahead and involving the staff members early on are key to a successful outsourcing venture (Guterl, 1996; Peisch, 1995). Therefore, Hypothesis 1, claiming that a lack of up-front planning is a source of process inefficiency, is supported by the collected survey data.

Hypothesis 2: stated that a misevaluation of the vendor's skills and capabilities may lead to poor efficiency is difficult to validate given the results obtained from the survey. Some publications have shown that poor outsourcing results can stem from a misunderstanding or miss-assessment of a vendor's abilities (Lacity and Hirschheim, 1993; Earl, 1996). Even though the Polish and Indian offices were rated below the AL Ltd. standard for their technical knowledge and abilities, it is important to take into account several complementary factors. The survey results from the SEO's indicate a clear and unanimous concern with access to certain computer tools, confidential or proprietary information, and AL Ltd. focal points for assistance. These facts make it difficult to judge whether the SEO skills are truly deficient or if the poor survey scores are a result of a lack of AL Ltd. support. Further analysis into this question is required in order to determine if this hypothesis is applicable to this study.

Hypothesis 3: postulates that a lack of close management and improvement of the customer-vendor relationship can lead to inefficiencies in the outsourcing process. The survey data, as well as information collected concerning company initiatives, clearly show that outsourcing activities are well managed and constantly improved. Reacting to resolve issues and continuously streamlining the process is extremely important in maintaining a healthy and efficient working relationship with the partner (Lankford and Parsa, 1999). This hypothesis is therefore not supported by the collected data, as AL Ltd. is making a noticeable effort in improving the customer-vendor relationship.

Hypothesis 4: shows a clear match between the literature findings and the survey results. In fact, Managers at AL Ltd. have not received any significant training in international management or managing cultural differences. Training and developing globally competent managers has now become essential given the increase in globalization (Sullivan and Tu, 1995). AL Ltd. mangers are currently not equipped with the proper skills required to better understand and administer cultural differences. Therefore, the collected data supports Hypothesis 4 and warns of process inefficiencies when proper management training is missing.

Hypothesis 5: touches on the importance of the quality of the shared information and on the level of support provided by either side (Bensaou, 1999). In both cases, the hypothesis is supported by the survey results. Although some information will remain confidential and cannot be shared, improvements can be made for the data that is cleared for public consumption but is currently difficult to obtain. Scores for the level of support varied among the SEO offices and AL Ltd. From the results obtained, it is interesting to note that the scores are inversed. When AL Ltd. rates an SEO as delivering good support (e.g. India at 5.6), that SEO gives AL Ltd. a lower score (India rates AL Ltd. at 4.8). The same is true but reversed for Poland. This may be due to the fact that when good support is provided by the SEO, AL Ltd. tends to take a step back. However, if AL Ltd. is not satisfied with the support of the SEO, closer monitoring and involvement is usually required. This may give the SEO the impression of a high level of support. 
Hypothesis 6: The literature has shown that problems may arise when communication and product quality or delivery expectations are not met (Ramarapu et al., 1997). Communication, both written and oral, has been raised as a concern by AL Ltd. employees. It was shown that poorly written memos or misunderstood instructions often lead to lost time and consequently hidden costs. The Polish office was rated slightly lower (4.4/7.0) than the Indian office (5.2/7.0) where English was established as the primary language in the office. Several activities such as phone conversations, language courses, and on-sites visits were suggested by the SEO employees as being helpful for developing their competency in English.

On-time delivery of services was also shown to be short of AL Ltd. standards. Concerns about meeting customer commitments were highlighted by AL Ltd. employees as a source of frustration. Both foreign offices were rated low for product delivery with India (4.6/7.0) scoring higher than Poland (3.9/7.0). Here again, one must be careful in how these results are interpreted. Dates for deliverables often dependant on AL Ltd. involved parties meeting their respective commitments. Several factors affecting the delivery record of the SEO's are in fact outside of their control as they are dependent on the participation of their AL Ltd. counterparts for assistance with proprietary information and computer tools.

The quality of the work done by SEO's was rated as satisfactory for the Indian office (6.0/7.0) but requires improvement at the Polish office (4.6/7.0). This perhaps could be due to the fact that the Polish office is two years younger than its counterpart in India and is still learning. On the other hand, one must also take into consideration the type of jobs being sent to each office as well as the training being provided to its employees. Overall, the data collected under this survey question shows good correlation with Hypothesis 6 due to several issues that are within the control of AL Ltd. and others however that may be beyond the company's influence.

Hypothesis 7: refers to process inefficiencies that are caused when the human resource aspect is mismanaged (Currie and Willcocks, 1997). The data collected shows that the main concern raised by SEO employees was in reference to their training and development. The general opinion at AL Ltd. reveals a perception that enough is being done to help and train SEO employees. The turnover rate was repeatedly mentioned by AL Ltd. participants in relation to training. The concern with a high turnover rate (especially in the Indian office) leads AL Ltd. employees to question the value of training. The feeling is that the investment in training and developing SEO workers will not pay in the long run as many leave for better opportunities after a short stay. The data collected concerning the management of the human resource aspect is in support of the hypothesis as both sides have raised important points pertaining to employee training and retention.

\section{Analysis Of Data Related To Cultural Differences (H8 - H11)}

Hypothesis 8: The objective of the survey question was to assess whether a higher Power Distance (PD) Index at the SEO's leads to a reluctance in questioning or challenging the authority of Canadian counterparts. The PD index is extremely high in India (72), followed by Poland (50), and then Canada (35), which exhibits a relatively low score (Hofstede, 1981). The data collected shows that Canadian employees are often frustrated with their counterparts for misunderstanding the intent of a job and not having asked questions. SEO employees often give the impression of walking away from meeting without having asked AL Ltd. the right questions. This is more evident for the Indian office than the Polish office. This data hence supports the Hofstede theory (1981) and this hypothesis by the fact that employee frustration and lost time are being caused by a difference in cultural behavior when it comes to Power Distance.

Hypothesis 9: presents the Individualism (IDV) index as a possible source of inefficiencies in the outsourcing process. A low IDV index can be interpreted as being less independent and having to rely on one's group or supervisor for decision making. Canadians tend to be highly individual and self-reliant people with a score of 75, followed by Polish at 55 and India at 43 (Hofstede, 1981). We notice here a noteworthy difference in these ratings when comparing Canadians with their foreign counterparts. This becomes evident when considering the survey results, which reveal the SEO's as having a low degree of autonomy. In fact, AL Ltd. employee expressed concern with the dependency of SEO workers on their Canadian counterparts. However, a note of caution is required here. These results should not be considered independently. The SEO's have raised several issues that hinder their degree 
of autonomy when assigned certain jobs. In particular, the limited access to information, the confidentiality/proprietary concerns with some aspects of shared technology, the limitation in computer tools licenses, and training. These roadblocks to autonomy should be taken into account when evaluating the SEO's performance. It is therefore difficult to judge whether this Hypothesis is truly supported by the survey data. However, since the concern of lack of SEO autonomy was raised by AL LTD. employees, the Hypothesis should be considered as valid and taken into account in the overall assessment.

Hypothesis 10: The Masculinity (MAS) index helps us understand the priority people place on certain aspects of their career. It becomes important when managing cultural differences and deciding on recognition methods. According to the Hofstede theory, Canadians and Indians share a similar MAS score at 48 and 50 respectively. On the other hand, Polish people exhibit a higher MAS index estimated at 60. The latter will mean that in Poland, people will place more importance on earnings, personal recognition, and career advancement rather than on cooperation among colleagues and job security. The data collected from the survey does not support Hypothesis 10 as there was no significant difference in the way the three offices rated the above criteria. AL Ltd. has placed earnings, career advancement, and personal recognition at the top of the priority list. Consequently, the MAS index is not a cause for differentiation between AL LTD. and the SEO's and should not be a source of process inefficiencies.

Hypothesis 11: The Uncertainty Avoidance Index (UAI) discussed here is an indication of the level of comfort when faced with unstructured situations or a lack of overall visibility. Canada and India have been assessed as having low UAI scores at 42 and 35 respectively, while Poland has a much higher score at 72 (Hofstede, 1981). Indian workers are more likely to adapt in an unstructured environment and more likely to take risks such as changing jobs. In fact, the voluntary turnover rate in the Indian office is much higher than the one in the Polish office. However, both offices raised similar concerns about the insufficient visibility they are given on projects. SEO employees work on individual tasks without necessarily knowing how each task fits in the overall project. Even though the survey results do not correlate with the Hypothesis, we do see that both SEO offices, despite their differences in UAI scores, share the concern of having to deal with an incomplete set of information required to execute their job. In other words, the UAI score is irrelevant since both SEO offices are equally concerned with the lack of visibility they are given. Note that this concern is covered under another survey question.

\section{Analysis Of Data Related To Motivation (H12 -H14)}

Hypothesis 12: stipulates that outsourcing can have a negative effect on the morale and motivation of company employees (Embleton and Wright, 1998; Elmuti and Kathawala, 2000). However, survey results from AL Ltd. employees do seem to indicate that neither morale nor motivation have been affected by working with the SEO's. The great majority of employees consider their SEO counterparts as providing valuable assistance in completing time-consuming jobs. Therefore Hypothesis 12 is not supported by the survey data.

Hypothesis 13: suggests outsourcing is a cause for increase in the employee turnover rate and eventual depletion of skilled workers (De Vries and Balazs, 1997; Mishra et al., 1998). The survey data however does not corroborate this hypothesis. The turnover rate at AL Ltd. has remained steady and relatively low for this industry for the past 5 years. Employees also felt safe about their future employment at AL Ltd. and would not consider employment elsewhere for the same salary. Therefore Hypothesis 13 is not supported by the survey data.

Hypothesis 14: The lack of incentive programs and intrinsic motivating factors offered by the company has been identified as a source of decreased employee motivation, performance and interest (Savery, 1996; Milne, 2007). For the questions under Hypothesis 14, employees were asked to provide feedback on company incentive programs and intrinsic motivators. Overall the data collected shows good employee satisfaction with the different incentive programs offered by AL Ltd. to both its Canadian and foreign employees alike. Canadian workers are also satisfied when it comes to recognition and other intrinsic motivators. AL Ltd. employees had favorable comments with respect to their feeling of satisfaction and achievement at the job they are performing. Foreign employees from both offices were somewhat satisfied with being recognized for doing a good job but were dissatisfied with their feeling of achievement at work. In fact, jobs sent abroad were considered as not being interesting nor challenging. This 
Hypothesis is therefore partially supported by the fact that intrinsic motivation at the SEO's requires some attention and improvement in order to enhance employee motivation.

As a summary of the above results, Table 2 demonstrates how well the literature-based hypotheses fit with the collected empirical data. A check mark indicates that the hypothesis is well supported by the survey results while an $\mathrm{X}$ indicates that the hypothesis is in conflict with the collected data.

Table 2: Summary of hypotheses validation through survey results

\begin{tabular}{|c|c|c|}
\hline H1. & $\begin{array}{l}\text { Poor efficiency of the outsourcing process is caused by a lack of upfront planning of requirements and } \\
\text { expectations. }\end{array}$ & $\checkmark$ \\
\hline H2. & Poor efficiency of the outsourcing process is caused by misevaluation of the vendor's skills and capabilities. & N/A \\
\hline H3. & $\begin{array}{l}\text { Poor efficiency of the outsourcing process is caused by a lack of close management and improvement of the } \\
\text { customer-vendor relationship. }\end{array}$ & $x$ \\
\hline H4. & $\begin{array}{l}\text { Poor efficiency of the outsourcing process is caused by a lack of proper management training in order to } \\
\text { efficiently deal with cultural differences. }\end{array}$ & $\checkmark$ \\
\hline H5. & $\begin{array}{l}\text { The efficiency of the outsourcing process is dependent on the quality of shared information and the } \\
\text { dedication of key players. }\end{array}$ & $\checkmark$ \\
\hline H6. & $\begin{array}{l}\text { Poor efficiency of the outsourcing process is caused by poor communication, different interpretations of } \\
\text { quality and time schedule expectations, and by information security and confidentiality constraints. }\end{array}$ & $\checkmark$ \\
\hline H7. & Poor efficiency of the outsourcing process is caused by mismanagement of the human resource aspect. & $\checkmark$ \\
\hline H8. & Poor efficiency of the outsourcing process is caused by a higher Power Distance index in India and Poland. & $\checkmark$ \\
\hline H9. & $\begin{array}{l}\text { Poor efficiency of the outsourcing process is caused by a difference in the Individual index between Canada } \\
\text { and the SEO countries. }\end{array}$ & $\checkmark$ \\
\hline H10. & $\begin{array}{l}\text { Poor efficiency of the outsourcing process is caused by a difference in the Masculinity index between } \\
\text { Canada and the SEO countries. }\end{array}$ & $x$ \\
\hline H11. & $\begin{array}{l}\text { Poor efficiency of the outsourcing process is caused by a difference in the Uncertainty Avoidance Index } \\
\text { (UAI) index between Canada and the SEO countries. }\end{array}$ & $x$ \\
\hline H12. & Outsourcing causes a decrease in employee morale and motivation. & $\mathbf{x}$ \\
\hline H13. & $\begin{array}{l}\text { Outsourcing is a cause of increase in turnover rate and an eventual depletion of highly skilled and } \\
\text { experienced workforce. }\end{array}$ & $x$ \\
\hline H14. & Incentive programs and enriching intrinsic motivation positively affect employee job satisfaction. & $\checkmark$ \\
\hline
\end{tabular}

\section{CONCLUSIONS AND RECOMMENDATIONS}

The survey results discussed in the above section have revealed some areas of the outsourcing process in need of attention. In this section, the main conclusions are summarized and recommendations are directed to organizations in general and AL Ltd. management in particular in an attempt to address the gaps and improve productivity. Management should work with employees within organized focus groups to further explore the main subjects of concern and create action plans aimed at implementing process improvements.

Listed below are the main areas where managerial action is required:

$\square \quad$ Up-front planning of tasks and communication of expectations.

$\square \quad$ Employee \& management training.

$\square \quad$ Information sharing.

$\square \quad$ Cultural differences due to Power Distance index.

$\square \quad$ Intrinsic motivation.

Employees have raised a concern about the lack of up-front planning and ill-defined expectations when it comes to outsourced tasks. This leads to significant lost time and employee frustration. Management should take the time to properly define and communicate the scope and objectives of a job prior to its release. Perhaps a process change is in order to implement a gate for a pre-design meeting for jobs that meet certain criteria (e.g. estimated design time, complexity, etc.). Furthermore, special attention should be paid to the overall SEO workload planning. A weekly meeting may be a vehicle where management is encouraged to maintain a list of AL Ltd. open SEO jobs 
and their status (i.e. \% completed, target date, waiting for information, etc.). This will generate an overall visibility on progress, roadblocks, as well as assist in balancing the workload amongst SEO groups.

Training is an issue that was raised by both sides. On the one hand, AL Ltd. managers are not receiving the adequate training to manage cultural differences when dealing with a foreign office. This should be addressed promptly in order to provide managers with the necessary skills to improve relationships with the SEO offices. On the other hand, SEO employees have complained about some specific needs where technical training is lacking and impeding on their performance. In particular, on-site visits should be encouraged so SEO employees can benefit from training alongside their AL Ltd. counterparts in addition to gaining exposure to hardware and an opportunity to practice the predominate (head office) language. The latter two reasons were highlighted by SEO employees as major issues lacking from today's working practices. Knowing that these visits can be expensive, special attention should be placed on the selection of candidates.

A contentious issue raised by SEO employees was the lack of information being provided to them. This often leads to delays when the information is necessary for completing a job but AL Ltd. focal points need to be consulted. Often times, the required information falls under confidentiality or proprietary rules that make it difficult to share with foreign entities. Even though the SEO offices are considered to be an extension of the main AL Ltd. office, they nevertheless are considered as foreign entities under the Controlled Goods Act. However, given that this topic was cited by SEO survey participants to be a significant factor of lost time, AL Ltd. management should reevaluate the type of information that can or cannot be shared in order to facilitate job completion.

Due to a higher Power Distance index in the SEO countries, employees from the foreign offices were found in some cases to be reluctant to raise questions when in meetings with their AL Ltd. counterparts. This leads to misunderstandings and discrepancies on the end results. Management should strive at promoting the "AL Ltd. culture", which may be done through joint team building exercises, encouraging debates during meetings, and emphasizing an open door policy for managers. The "AL Ltd. culture" is already evident at the SEO's but needs to be continuously encouraged until it becomes an integral part of the foreign corporate work culture.

Lastly, AL Ltd. management should address intrinsic motivation at the SEO offices. Improvements can be made towards recognizing and rewarding employees for exceptional work. Small monetary rewards or recognition ceremonies have been identified as effective by survey participants. Moreover, effort should be invested towards creating a more challenging work environment where employees can gain a sense of achievement in their work. That can be done by gradually increasing the complexity of the jobs and the degree of involvement of SEO employees. By building experience and confidence, SEO workers will find themselves more involved in the creative rather than the mechanical part of the job. Essentially both groups and the organization gain the competitive advantage required in business processing outsourcing.

\section{AUTHOR INFORMATION}

\section{Dr. Steven H. Appelbaum}

Professor of Management and Senior Concordia University Research Chair in Organizational Development John Molson School of Business, Concordia University, Montreal, Quebec, Canada, H3G 1M8

Anis Samaha, MBA Project Engineer, Pratt \& Whitney Canada Corp. 1000 Marie-Victorin, Longueuil, Quebec, Canada, JAG1A1

\section{REFERENCES}

1. Bensaou, M. (1999), "Portfolios of buyer-supplier relationships", Sloan Management Review, Vol. 40 No. 4, pp. 35-44.

2. Currie, W. and Willcocks, L.P. (1997), New Strategies in IT Outsourcing: Major Trends and Global Best Practice - Report, Business Intelligence Ltd, London. 
3. De Vries, M. and Balazs, K. (1997), "The downside of downsizing”, Human Relations, Vol. 50 No. 1, pp. 11-50.

4. Deloitte Consulting (2005), Calling a Change in the Outsourcing Market, New York.

5. Diamond Consulting (2005), 2005 Global IT Outsourcing Study, Temecula, California.

6. Earl, M.J. (1996), “The risk of outsourcing IT”, Sloan Management Review, Vol. 37 No. 3, pp. 26-32.

7. Elmuti D. and Kathawala Y. (2000),"The effects of global outsourcing strategies on participants' attitudes and organizational effectiveness", International Journal of Manpower, Vol. 21 No. 2, pp. 112-128.

8. Embleton, P.R. and Wright, P. C. (1998), "A practical guide to successful outsourcing”, Empowerment in Organizations, Vol. 6 No. 3, pp. 94-106.

9. Franceschini F., Galetto M., Pignatelli A. and Varetto M., (2003) "Outsourcing: Guidelines for a Structured Approach", Benchmarking: An International Journal, Vol. 10 No. 3, pp. 246-260.

10. Friedman, T.L. (2005), "The World is Flat: A Brief History of the Twenty-First Century", Farrar, Straus and Giroux-Macmillan Publishers, New York.

11. Guterl, F. (1996), "How to manage your outsourcer”, Datamation, pp. 79-83.

12. Hofstede, G. (1981), “Culture's Consequences: International Differences in Work-related Values”, Academy of Management Review, Vol.6, No.4, pp. 681-683.

13. Lacity, M.C. and Hirschheim, R. (1993), "Beyond the Information Systems Outsourcing

14. Bandwagon", Sloan Management Review, Vol. 35 No. 1, pp. 73-86.

15. Lankford, W.M. and Parsa F. (1999), “Outsourcing: a primer”, Management Decision Vol. 37 No. 4, pp. 310-316

16. Linder J.C, Cole M.I., Jacobson A.L.,(2002), “Business Transformation Through Outsourcing”, Strategy \& Leadership, Vol. 30 No. 4, pp.23-28.

17. Milne, P. (2007),"Motivation, incentive and organizational culture”, Journal of Knowledge Management, Vol. 11 No. 6, pp. 28-38.

18. Mishra, A.K. and Mishra, K.E. (1994), "The role of mutual trust in effective downsizing Strategies", Human Resource Management, Vol. 33 No. 2, pp. 261-79.

19. Peisch, R. (1995), "When outsourcing goes awry”, Harvard Business Review, Vol. 73 No. 3, May-June, pp. 24-30.

20. Power, M., Bonifazi, C. and Desouza, K.C. (2004), "The ten outsourcing traps to avoid", Journal of Business Strategy, Vol. 25 No. 2, pp. 37-42

21. Ramarapu, N., Parzinger, M. and Lado, A. (1997), "Issues in foreign outsourcing”, Information Systems Management, pp. 7-31.

22. Savery, L.K. (1996), "The congruence between the importance of job satisfaction and the perceived level of achievement", Journal of Management Development, Vol. 15 No. 6, pp. 18-27.

23. Sullivan, S.E. and Tu, H.S. (1995), "Developing globally competent students: a review and recommendation", Journal of Management Education, Vol. 19 No. 4, pp. 473-93.

24. Vail, P. (1989), Managing as a Performing Art, Jossey-Bass, San Francisco, CA. 